\title{
Ectopic pregnancy after levonorgestrel emergency contraception
}

\author{
Ahmet Karatas $^{1 *}$, Halil Ilgın², Tulay Ozlu ${ }^{1}$ \\ ${ }^{1}$ Abant Izzet Baysal University Medical Faculty, Department of Obstetrics and Gynecology, Bolu, Turkey \\ ${ }^{2}$ Private Akdeniz Sifa, Konyaaltı Surgery Medical Center, Department of Obstetrics and Gynecology, Antalya, Turkey
}

Received: 23 September 2013, Revised: 27 September 2013

Accepted: 11 October 2013

\author{
*Correspondence: \\ Dr. Ahmet Karatas, \\ E-mail: akaratas1973@hotmail.com
}

(C) 2013 Karatas A et al. This is an open-access article distributed under the terms of the Creative Commons Attribution Non-Commercial License, which permits unrestricted non-commercial use, distribution, and reproduction in any medium, provided the original work is properly cited.

\begin{abstract}
Levonorgestrel Emergency Contraception (LNG-EC) is the safest and the most commonly used oral regimen that can be used after an unprotected intercourse. Although it is highly effective, failures can occur especially if it is used in the peri /or postovulatory period. It can not inhibit ovulation if used in these periods and the altered tubal motility together with the ciliary dysfunction can prevent the transfer of the fertilized ovum from the fallopian tube to the endometrial cavity, causing an ectopic pregnancy, which is one of the important concerns after failed LNG-EC. This risk was reported not to be higher than the risk of ectopic pregnancy observed in the general population, but the users of this medication should still warned about this risk. Here we report a case of ectopic pregnancy from Turkey after midcyclic use and failure of LNG-EC.
\end{abstract}

Keywords: Ectopic pregnancy, Levonorgestrel, Emergency contraception

\section{INTRODUCTION}

Emergency contraception (EC) is widely used to prevent unwanted pregnancy after an unprotected intercourse occurring due to several reasons such as an error occurring during use of the current contraceptive method or use of no contraception. The most commonly used oral regimen, levonorgestrel emergency contraception (LNGEC), is an extremely safe method that has been used for five decades for this purpose. ${ }^{1}$ The main mechanism of action of LNG-EC is delaying or inhibiting ovulation ${ }^{2}$ and to be able to show this effect, it should be received 23 days before the LH peak. ${ }^{2}$ Its effects after the peri /or postovulatory period are accepted to be unclear, while changes in the tubal motility and ciliary dysfunction in the tubal epithelium are among the considered mechanisms. $^{2}$ Therefore increased failure rates, and occurrence of an ectopic pregnancy may be seen with the peri or postovulatory use of LNG-EC. ${ }^{2}$
Ectopic pregnancy following LNG-EC in case of failure is one of the risks that the patients using this medication should be aware of. Up to date, about 18 cases of ectopic pregnancies are reported following LNG-EC. ${ }^{3}$ Here we report a similar case from Turkey that occurred after the midcyclic use of LNG-EC.

\section{CASE REPORT}

A 29-year-old G3P1L1A1 woman with regular menstrual periods admitted to the clinic to ask about EC 10 hours after an intercourse complicated by condom puncture. She was at the mid-cyclic period. To prevent an unwanted pregnancy, LNG-EC (Norlevo ${ }^{\text {Abdi Ibrahim } 750}$ $\mu \mathrm{cg}$, two pill) was prescribed, and she was told to get the 2 pills at the same time and to readmit in case of more than a week delay in the menstrual period or lower abdominal pain which could be signs of failure of EC as well as being normal side effects. She readmitted with 10 day retardation in the menstrual period. $\beta$-hCG at admission was positive $(99 \mathrm{mIU} / \mathrm{ml})$. She decided to 
continue the pregnancy, and she was advised to come for a follow-up $\beta$-hCG 2 days later because of a theoretical risk of ectopic pregnancy after failed LNG-EC. She admitted with vaginal bleeding 4 days later, and the $\beta$ hCG was $273 \mathrm{mIU} / \mathrm{ml}$. She refused hospitalization, and wanted to be followed up as an outpatient. Two days later, she admitted with increased vaginal bleeding. The pelvic examination revealed no tenderness in the adnexial areas. On transvaginal ultrasound, endometrium was 8 $\mathrm{mm}$ with no pathological appearance in the adnexial areas. Dilatation and curettage was performed and the material was sent for pathological examination to rule out an incomplete abortion or ectopic pregnancy. $\beta$-hCG was 237 and $219 \mathrm{mIU} / \mathrm{ml}, 7$ days and 9 days after the procedure. The curettage specimen was reported as decidual endometrium with no trophoblastic tissue. Upon these findings, $50 \mathrm{mg} / \mathrm{m} 2$ single dose intramuscular methotrexate was administered with a diagnosis of ectopic pregnancy. Two weeks later clinical and the laboratory parameters of the patient returned to normal.

\section{DISCUSSION}

LNG-EC is a highly effective method of EC, but its efficacy depends on the period of the menstrual period when it is used and as well as the time interval between the intercourse and the intake of the drug. Using this medication in the follicular period, not more than a few days close to the LH surge, is the best since this kind of use enables the inhibition of ovulation which is its main mechanism of action. ${ }^{2}$ As the time that passes after the intercourse until the intake of the drug which is the second important factor increases, its efficacy decreases. LNG $1.5 \mathrm{mg}$ was reported to prevent $95 \%, 85 \%$ and $58 \%$ of the expected pregnancies if taken within $24 \mathrm{~h}, 25-48 \mathrm{~h}$ and $49-72 \mathrm{~h}$ of sexual intercourse, respectively. ${ }^{4}$ Our patient admitted $10 \mathrm{~h}$ after the intercourse and took the drug within the first $24 \mathrm{~h}$, however, she was at midcyclic period, which was probably the pre or the postovulatory period. So, the drug failed to inhibit the ovulation.

LNG-EC is a very safe method of EC with very negligible side effects like mild nausea, vomiting, dizziness, headache, breast tenderness, abdominal pain and fatigue. ${ }^{5}$ Early (15\%) or delayed (28\%) menses because of the inhibition of ovulation are also among these side effects. ${ }^{4}$ The menstrual delay can be more than 7 days in $13 \%$ of the cases ${ }^{4}$ and this is a source of anxiety about failure in patients using this method. Although delay in menstruation is one of the normal side effects, the patient should be informed that this can also be a sign of failure of the drug, so she needs to visit a clinician if the delay lasts more than a week. ${ }^{5}$
After the occurrence of a few cases of ectopic pregnancies following the failure of LNG-EC, it is recommended in several countries that in case of a conception following a failed EC with LNG, the possibility of ectopic pregnancy should be considered. ${ }^{6}$ Although the risk of ectopic pregnancy increases with alterations in the tubal motility and ciliary dysfunction caused by $\mathrm{LNG}$, in a systematic review conducted by Cleland et $\mathrm{al}^{6}{ }^{6}$ ectopic pregnancy rate is reported as $1 \%$ among women exposed to LNG-EC, while the risk of ectopic pregnancy among women that did not use EC pills was 0.8 to $2 \%$. Therefore, they concluded that risk of ectopic pregnancy after failed EC pills was not greater than the risk observed in the general population.

Therefore, it is known that, LNG-EC effectively decreases the overall possibility of pregnancy (both for intrauterine and ectopic) after an unprotected intercourse. In case of failure, the risk that this pregnancy will be ectopic may have slightly increased because of the effects of LNG over tubal motility and ciliary functions, but this risk is not greater than that of the general population. To be on the safe side, patients should be warned about the importance of a follow up admission if the menstruation delays more than a week or if lower abdominal pain occurs. ${ }^{(5)}$ Our case is another example of this rare scenario.

\section{REFERENCES}

1. Glasier A. Emergency contraception: clinical outcomes. Contraception 2013;87(3):309-13.

2. Gemzell-Danielsson $\mathrm{K}$, Berger $\mathrm{C}, \mathrm{P} \mathrm{G} \mathrm{L} \mathrm{L}$. Emergency contraception - mechanisms of action. Contraception 2013;87(3):300-8.

3. Sarkar NN. The emergency contraceptive drug, levonorgestrel: a review of post-coital oral and pericoital vaginal administration for prevention of pregnancy. J Obstet Gynaecol 2011;31(8):703-7.

4. Task Force on Postovulatory Methods of Fertility Regulation. Randomised controlled trial of levonorgestrel versus the Yuzpe regimen of combined oral contraceptives for emergency contraception. Lancet 1998;352(9126):428-33.

5. American College of Obstetricians and Gynecologists. ACOG Practice Bulletin No. 112: Emergency contraception. Obstet Gynecol 2010;115(5):1100-9.

6. Cleland K, Raymond E, Trussell J, Cheng L, Zhu H. Ectopic pregnancy and emergency contraceptive pills. A systematic review. Obstet Gynecol 2010;115(6):1263-6.

DOI: $10.5455 / 2320-1770 . i j r \operatorname{cog} 20131262$

Cite this article as: Karatas A, Ilgin H, Ozlu T. Ectopic pregnancy after levonorgestrel emergency contraception. Int J Reprod Contracept Obstet Gynecol 2013;2:749-50. 